\title{
A IMPORTÂNCIA DA PRESERVAÇÃO DO PATRIMÔNIO INDUSTRIAL
}

Willian da Silva, Yeda Ruiz Maria

Universidade do Oeste Paulista - UNOESTE, Curso de Arquitetura e Urbanismo, Presidente Prudente, SP. Email: will.silvaa1@hotmail.com, yeda_rm@hotmail.com.

\section{RESUMO}

Entende-se como patrimônio histórico todas as expressões materiais e imateriais produzidas, tais como construções, artefatos, objetos, danças, comidas típicas e demais aspectos que sejam capazes de representar uma geração. O objetivo deste artigo é de expor a importância da preservação do patrimônio histórico industrial para a transmissão de conhecimentos às futuras gerações. A metodologia constou através do estudo de teóricos da preservação e restauração do patrimônio contando com análises qualitativas. Os resultados mostraram a importância da proteção e preservação de bens materiais e imateriais, que garantem a preservação da memória coletiva.

Palavras-chave: Patrimônio Histórico; Patrimônio Cultural; Patrimônio Industrial; Intervenção; Ferrovia.

\section{THE IMPORTANCE OF PRESERVATION OF HISTORICAL HERITAGE}

\begin{abstract}
It is understood as historical patrimony all the material and immaterial expressions produced, such as constructions, artifacts, objects, dances, typical foods and other aspects that are capable of representing a generation. The purpose of this article is to expose the importance of the preservation of historical industrial heritage for the transmission of knowledge to future generations. The methodology consisted of the study of preservation and restoration theorists, counting on qualitative analyzes. The results showed the importance of the protection and preservation of material and immaterial goods, which guarantee the preservation of collective memory.
\end{abstract}

Keywords: Historical Patrimony; Cultural Heritage; Industrial Patrimony; Intervention; Railroad. 


\section{INTRODUÇÃO}

Segundo o website oficial do IPHAN (2014), por meio do patrimônio histórico é possível conhecer a cultura de um determinado grupo ou até mesmo de uma sociedade, como também todo o decorrer de sua história. Mas nem sempre esses bens patrimoniais tem sua importância reconhecida pela sociedade e por isso chegam ao estado de abandono. O patrimônio industrial, ou seja, todos os bens materiais e imateriais resultantes da industrialização foram de extrema importância para o desenvolvimento nacional, tanto no âmbito cultural quanto econômico e tecnológico. Entretanto, com a substituição do sistema ferroviário pelo rodoviário os equipamentos que eram ligados à ferrovia foram esquecidos, principalmente na sua importância histórica para o desenvolvimento nacional, como também na falta de manutenção e adaptação de uma nova função para este setor (MONASTIRSKY, 2006).

Neste contexto, o objetivo foi destacar a importância da preservação do patrimônio histórico industrial como sustentação da memória coletiva da sociedade. A metodologia constou a partir do estudo de teóricos renomados que definem patrimônio histórico e industrial assim como a preservação, o restauro e a proteção destes bens.

O estudo desses teóricos reforçou ainda mais a importância da preservação e proteção do patrimônio histórico como meio de garantir a autenticidade histórica e cultural de uma determinada sociedade ou grupo, impedindo assim, que o mesmo sofresse alterações ou intervenções que fragilizassem sua originalidade ou produzisse um falso artístico.

\section{METODOLOGIA}

A metodologia aconteceu a partir do estudo de teóricos renomados, que definem patrimônio histórico cultural, patrimônio industrial, assim mesmo como a preservação, o restauro e a proteção destes bens. O estudo desses teóricos reforçou ainda mais a importância da preservação e proteção do patrimônio histórico como meio de garantir a autenticidade histórica e cultural de uma determinada sociedade ou grupo, impedindo assim, que o mesmo sofresse alterações ou intervenções que fragilizassem sua originalidade ou produzisse um falso artístico.

\section{RESULTADOS}

O artigo 216 da Constituição Federal Brasileira (1988) define patrimônio histórico cultural como bens de natureza material e imaterial, tomados individualmente ou em conjunto, portadores de referência à identidade, à ação e à memória dos diferentes grupos formadores da sociedade brasileira. O patrimônio histórico material consiste em museus, bibliotecas, universidades e todo material tangível. De outro lado, o patrimônio de caráter imaterial, consiste nas diversas expressões culturais, como os saberes, os costumes, as festas, as danças, as lendas e todo bem intangível. Já o patrimônio artístico refere-se aos bens de valor artístico e ao patrimônio natural, como por exemplo, as obras de pintura, arquitetura ou esculturas (IPHAN, s/a)

Existem diversos órgãos que objetivam a conservação e a preservação de bens patrimoniais. No Brasil, o reconhecimento destes bens é gerido pelo Instituto Histórico e Artístico Nacional (IPHAN) e vinculado ao Ministério da Cultura. Quando a sociedade reconhece a importância de um bem, o mesmo é sujeito ao processo de tombamento através das organizações de preservação, com o intuito de proteger e salvaguardar a história. Através da preservação, objetiva-se a preservação de um patrimônio para que ele 
possa transmitir conhecimento às futuras gerações. No caso do patrimônio histórico material, a preservação protege a obra de reformas, demolições, intervenções e quaisquer alterações que descaracterizem a obra ou afetem sua originalidade. $\mathrm{O}$ tombamento de um bem como patrimônio histórico é a garantia de perpetuação do mesmo (IPHAN, s/a).

Considerado como patrimônio industrial, a ferrovia e os equipamentos produzidos pelo setor ferroviário, surgiram no século XIX, e o que foi produzido neste período, servem como testemunho de um período da história da arquitetura marcada pela transposição de estilos e de materiais, como a alvenaria de tijolo, o ferro, e outros materiais industrializados, que representaram a racionalização e auxiliaram no estabelecimento de uma nova práxis construtiva (KUHL, s/a). A indústria foi, sem dúvida, um importante legado da estrada de ferro no início do século XX. Nas cercanias da linha do trem e das indústrias, os povoados, bairros e cidades surgiam sem estar nos planos da ferrovia e sem dar importância ao desenvolvimento de núcleos urbanos ao redor da linha (MONASTISKY, 2006). A partir de 1920, cresceu consideravelmente o número de estações ferroviárias e serviços ligados à este para atender a demanda das novas fábricas que surgiam com grandes plantas industriais. $O$ apelo para o aumento de transporte de passageiros vinha das industrias, que precisavam atrair a massa de trabalhadores espalhados pela capital. Além disso, as ferrovias eram implantadas em áreas específicas e estratégicas para dinamizar uma estrutura de produção e exportação das indústrias (MONASTIRSKY, 2006).

Foi assim que a ferrovia também participou no processo de urbanização, formando novas cidades, devido às linhas de penetração para o interior, que surgiram em função das atividades econômicas pelas quais a ferrovia foi implantada ou por função logística do funcionamento da própria rede ferroviária. Ela também auxiliou no papel material e social de pequenas e médias cidades, que com o tempo, substituíram o modelo rural ao urbanizarem-se (MONASTIRSKY, 2006). Em alguns casos, os próprios equipamentos ferroviários foram os responsáveis pela concentração das primeiras atividades ao redor da estação, sendo então, o responsável pela urbanização, pois era nas estações ferroviárias que concentravam-se as primeiras atividades urbanas (GHIRARDELLO, 2001).

O interesse pela preservação do patrimônio industrial é recente e deve ser visto como uma ampliação no acervo de bens culturais, porém, o debate em relação à preservação desse período teve início tardio na Inglaterra, em meados dos anos 1950, ganhando maior vigor e atenção pública a partir dos anos 1960, quando importantes testemunhos da arquitetura industrial foram demolidos. A partir disso, o movimento se consolidou e se ampliou para vários países, que realizaram inventários sistemáticos do patrimônio industrial. Desde 1960, significativos esforços foram feitos para definir o patrimônio industrial, estabelecer parâmetros cronológicos, elaborar registros e estudos, com o objetivo de definir o que é patrimônio industrial e por que preservá-los (KUHL, s/a).

De acordo com o estudo realizado por Kuhl $(2010$, p. 25), pondera-se que:

O patrimônio industrial compreende os vestígios da cultura industrial que possuem valor histórico, tecnológico, social, arquitetônico ou científico. Estes vestígios englobam edifícios e maquinaria, oficinas, fábricas, minas e locais de tratamento e de refinação, entrepostos e armazéns, centros de produção, transmissão e utilização de energia, meios de transporte e todas as suas estruturas e infraestruturas, assim como os locais onde se desenvolveram atividades sociais relacionadas com a indústria, tais como habitações, locais de culto ou de educação. 
A arquitetura industrial é de interesse à várias áreas do conhecimento - em especial às humanidades - pois está ligada à antropologia, à história, à ciências, à engenharia, à arte, à arquitetura, às cidades, entre outros assuntos importantes. O processo de preservação tem o intuito de registrar, revelar, preservar e valorizar o contexto industrial(CHOU et al., s/a). Segundo Lemos (2010, p. 28) "é dever de patriotismo preservar os recursos materiais, e as condições ambientais em sua integridade, sendo exigidos métodos de intervenção capazes de respeitar o elenco de elementos do Patrimônio Cultural", pois este ato é necessário para compreensão da memória social, protegendo o que se considera significativo, dentro do vasto repertório de elementos que compõem o patrimônio histórico, cultural e artístico (LEMOS, 2010). A proteção através do tombamento é vista como um ato de respeito pelo passado, interpretado no presente e voltado para o futuro, para que os bens culturais continuem efetivos e fidedignos suportes da memória coletiva (KUHL, s/a).

A preservação tem por objetivo a conservação e revelação dos valores estéticos e históricos do monumento, e é fundamentado no respeito pelo material original e pelos documentos autênticos. No que diz respeito à arquitetura, o projeto de preservação exige maestria e capacidade de interpretação das formas, sendo respeitoso, sensível e respeitando os aspectos formais e documentais da obra. Quaisquer alterações, remoções, inserções e uso da criatividade deve ser consequência da abordagem multidisciplinar fundamentada (KUHL, s/a).

Infelizmente, hoje em dia, o valor histórico e de memória social do patrimônio são de importância apenas para pessoas ligadas ao meio da arte, por serem mais cultas ou conhecedoras do meio, como arquitetos, artesãos, historiadores, arquipélagos, etc. A falta de reconhecimento da importância da obra faz com que o patrimônio seja esquecido e consequentemente sofra desgastes irreversíveis causados pelas intempéries do tempo e das ações humanas.

Quando os órgãos competentes ou sociedade entendem a importância do bem, pode ser tarde para recuperar os aspectos originais da obra, porém, o reconhecimento deste valor é importante mesmo quando tardio, pois evita a continuidade dos desgastes e protege os remanescentes da obra através do tombamento (LEMOS, 2010).

O reconhecimento do complexo ferroviário como patrimônio cultural é sustentado pela memória coletiva, nas lembranças da sociedade articulada com as individuais, que assim, distingue os espaços ocupados pela ferrovia como lugares importantes na memória (MONASTIRSKY, 2006). As edificações industriais são as testemunhas das comunidades por estabelecerem identidade local, representando o passado e explicando a existência das comunidades ao longo da malha ferroviária. A preservação deve acontecer através de iniciativa da população, desde que seja reconhecido o valor de memória social do patrimônio, e assim, prover a proteção através do tombamento, evitando possíveis descaracterizações, tais como intervenções que afetem a originalidade da obra, produzam um falso artístico e dificultem a transmissão de conhecimentos do passado para gerações futuras. Portanto, entende-se que quanto antes se reconhece a importância de um patrimônio cultural, mais características desta obra podem ser preservadas, agregando assim mais valor e originalidade ao patrimônio em seu contexto histórico (LEMOS, 2010).

\section{DISCUSSÃO}

O patrimônio histórico, cultural e artístico abrange um vasto acervo tangível e intangível à ser preservado, sendo que tudo aquilo que for intangível serve como transmissão de conhecidos de forma oral ou teórica. No caso do patrimônio tangível (ou 
material), é possível utilizá-lo como forma de representação para educação, que, aliás, é a maneira como os museus, centros de cultura e outros equipamentos culturais preservam a memória coletiva de uma sociedade, utilizando-os para a transmissão de conhecimentos às futuras gerações.

\section{CONCLUSÃO}

Depois de entender a importância da preservação e proteção do patrimônio histórico industrial, é impossível questionar a importância da preservação e proteção destes bens culturais. Segundo Monastirsky (2006), além de terém contribuído para uma nova práxis construtiva, este setor também foi responsável pelo desenvolvimento socioeconômico, tecnológico e por atrair a população e demais atividades para o ponto de centralidade, que correspondia aos locais de indústrias e produção.

É de suma importância que este setor seja restaurado e preservado em sua integridade, para que sirva como sustentação da memória coletiva e social, garantindo assim, que sua contribuição no passado para o desenvolvimento nacional seja contada com autenticidade e representação física de seus locais de produção para as futuras gerações. Segundo Lemos (2010, p. 28) "é dever de patriotismo preservar os recursos materiais e as condições ambientais em sua integridade." A proteção através do tombamento é vista como um ato de respeito pelo passado, interpretado no presente e voltado para o futuro, para que os bens culturais continuem efetivos e fidedignos suportes da memória coletiva (KUHL, s/a).

\section{REFERÊNCIAS}

BRASIL. Constituição (1988). Constituição da República Federativa do Brasil. Brasília, DF: Senado Ferderal: Centro Gráfico, 1988.

CHOU, J.; ANDRADE, J. Intervenção urbana e patrimônio cultural. Sergipe: PRODEMA-UFS, s/a.

GHIRARDELLO, N. À beira da linha: formações urbanas da Noroeste Paulista. São Paulo:Editora UNESP, 2002. https://doi.org/10.7476/9788539302420.

IPHAN, Brasília. Disponível em: <http://portal.iphan.gov.br/pagina/detalhes/218>. Acesso em 05 ago. 2018.

$\mathrm{KUHL}$, B. Algumas questões relativas ao patrimônio industrial e à sua preservação. São Paulo: IPHAN, s/a.

KUHL, B. Patrimônio Industrial: algumas questões em aberto. São Paulo: USJT, 2010.

LEMOS, C. O que é patrimônio Histórico, 2. ed. São Paulo: Brasiliense, 1981. 127 p.'

MONASTIRSKY, L. Ferrovia: Patrimônio Cultural. Florianópolis: UFSC, 2006. 